\title{
Modern Polorization Policies and Spatial Development: Study of the Industrial Clusters Policy-Karbala Case Study
}

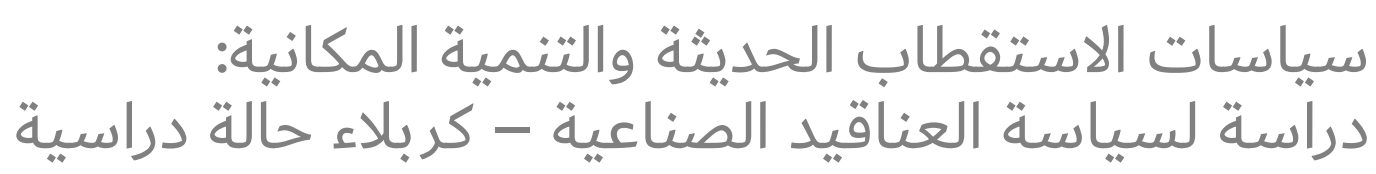
Zahraa Imad Hussian

زهراء عماد حسين

Center of urban and regional planning for postgraduate studies

مركز التخطيط الحضري والاقليمي للدراسات العليا، العراق - بغداد

Corresponding Author:

Zahraa Imad Hussian

Zahraa_imad87@yahoo.com

Received: 28 December 2017

Accepted: 2 February 2018

Published: 1 May 2018

Publishing services provided by Knowledge $\mathrm{E}$

(c) Zahraa Imad Hussian. This article is distributed under the terms of the Creative Commons

Attribution License, which permits unrestricted use and redistribution provided that the original author and source are credited.

Selection and Peer-review under the responsibility of the Urban Planning Iraq Conference Committee.

\section{Abstract}

Small or medium enterprises are considered to be one of the entrances to development. Many developed and developing countries have adopted and developed them and provide an investment environment for them to promote their contribution to the economic development process. The research sought to indicate a policy related to the development of these institutions, which are industrial clusters as one of the policies of modern polarization and statement of the concept and types and mechanisms of work down to the advantages and objectives To solve the problem of research, there is no clear perception of the modern polarization policies and its importance in the development of the region. And to prove the hypothesis of research that whenever industrial clusters can be applied whenever development is achieved. The hypothesis was proven by the collection of data on the industry situation in Karbala Governorate. The research focused on achieving the objective of this study, namely, whether there is a possibility to adopt industrial clusters as a development policy in the governorate of Karbala. The answer to the question was obtained through the statement of the most important determinants and success factors of the industrial clusters And then analyze the reality of potentials and determinants (strengths, weaknesses, opportunities, threats) of the industrial sector of the Karbala Governorate It was concluded that, despite the important role of industrial clusters in development, but the determinants and weaknesses in the industrial sector exceeded the strengths. Therefore there was a conclusion that the application of this policy needed an appropriate environment for its application. Thus, it can be said that there are opportunities for its applicability, but it takes a long time to take advantage of them. 
تعتبر المؤسسات الصغيرة أو المتوسطة كأحد مداخل التنمية فقد اعتمدت العديد من الدول المتقدمة أو النامية على تطويرها وتوفير المحيط الاستثماري لها وذلك لترقية مساهمتها في عملية التنمية الأقتصادية لذلك حاول البحث التطرق لسياسة ترتبط بتطور هذة المؤسسات وهي العناقيد الصناعية كأحد سياسات

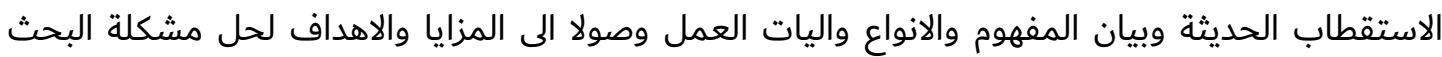

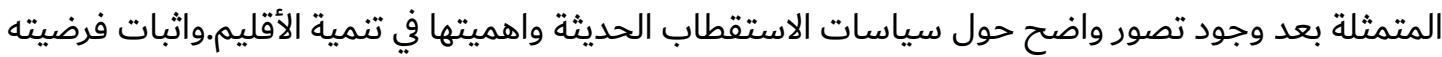

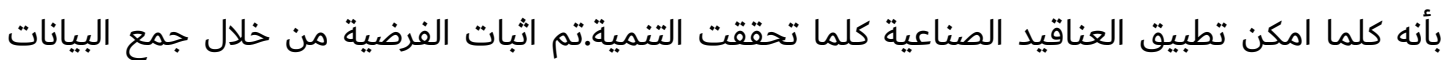

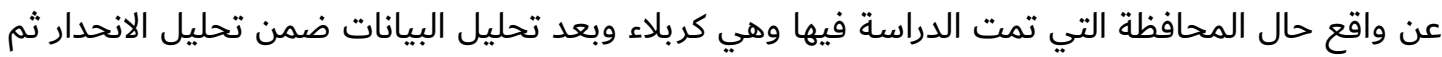

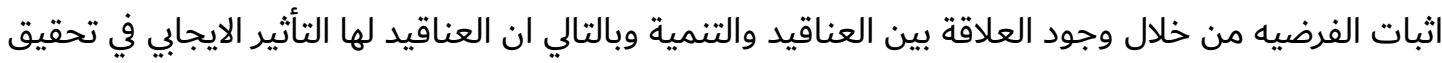
التنمية الاقتصادية, ركز البحث على تحقيق الهدف من هذه الدراسة وهي هل هنالك امكانية اعتماد العناقيد

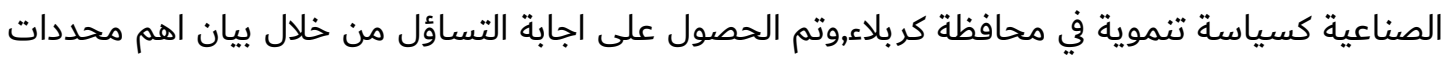

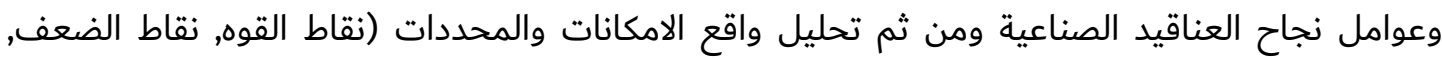

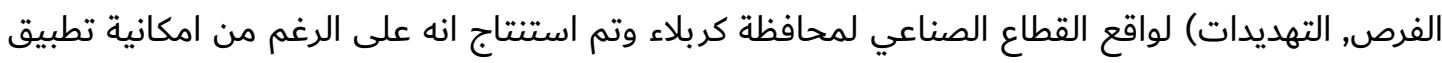

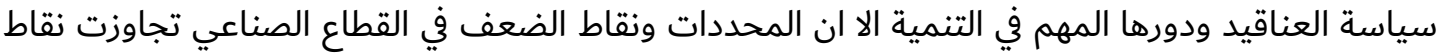

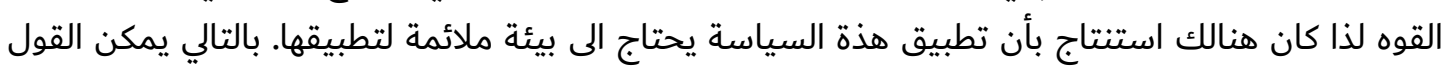

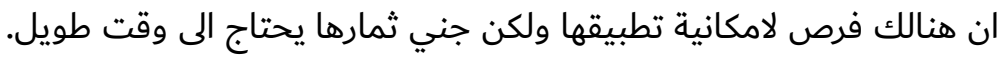

Keywords: polarization, industrial clusters, development.

الكاتمات المفتاحية: الاستقطاب, العناقيد الصناعية, التنمية

تتميز الصناعة عن القطاعات الاخرى بمساهمتها في تحقيق أساس النمو الأقتصادي ويعتبر التصنيع الجوهر في النمو الأقتصادي وخصوصا بالنسبة للدول النامية و يمكن من خلاله الأرتقاء اجتماعيا وثقافيا.

مفهوم الأستقطاب

يمكن تلخيص فكرة الأستقطاب في أن النمو المتسارع للصناعات القائدة يعمل على اجتذاب وحدات صناعية

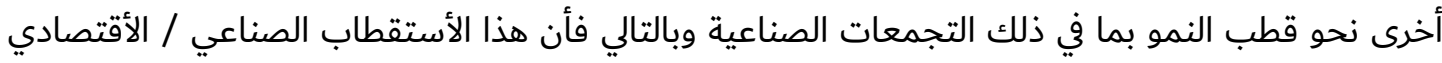
يؤدي الى استقطاب مكاني / جغرافي مع تدفق الموارد الى أماكن أخرى غير محدودة داخل الأقليم.(1).

فكرة الأستقطاب

فكرة نظرية الأستقطاب طورت على أفتراض أن النمو الأقتصادي لايمكن أن يكون في كل مكان وفي وقت

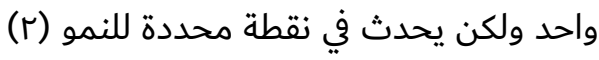


شهدت الدراسات الجغرافية الاقتصادية التي تعني بالمواقع الصناعية نقلة نوعية في إبراز أهمية التركز

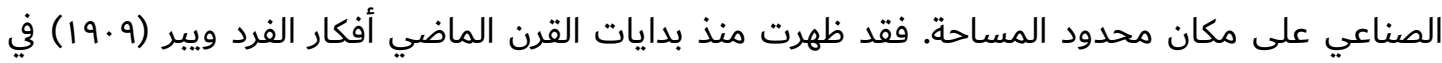

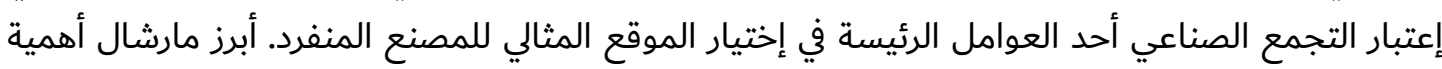

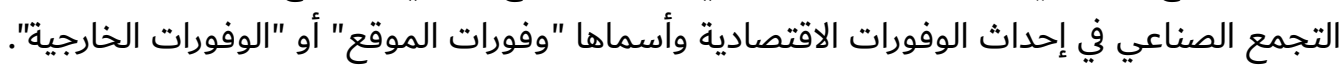
وما زال الإقتصاديون يطلقون على التجمعات الصناعية مفهوم "تجمع مارشال" تقديرلآرائه في هذا المجال

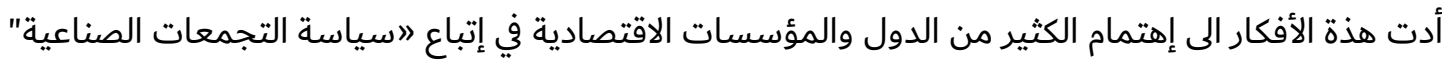

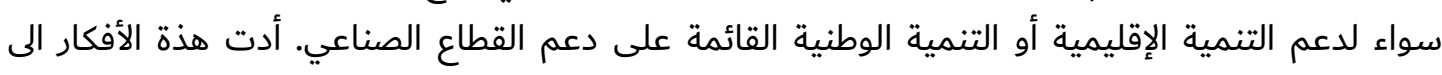

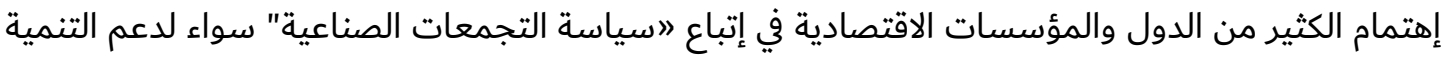

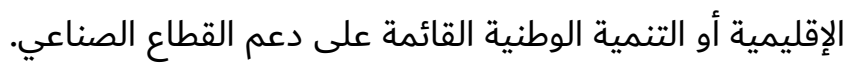

نشأة التجمعات الإقتصاديه

لابد من بيان لتباين في وجهات النظر في نشأة التجمعات الأقتصادية بشكل عام قبل التطرق لنشأة التجمع العنقودي كشكل متقدم ومتخصص لايد منها.

• ما طرحة 1991 Krugman الذي يعلل نشأة التجمع بما يلي: تميل المنشآت الى التركز في موقع

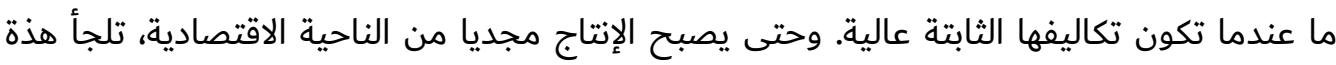

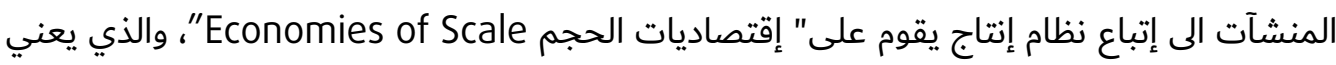

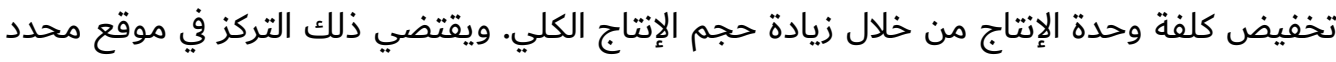

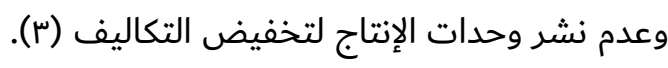

• تتركز المنشآت الاقتصادية بشكل أكبر عندما يكون إرتباطها بمواقع ثابتة (مواقع الموارد الطبيعية)..

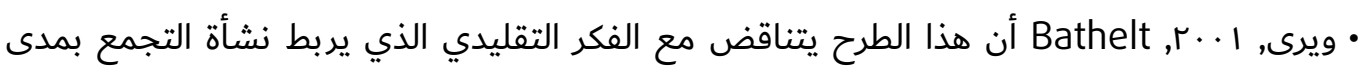

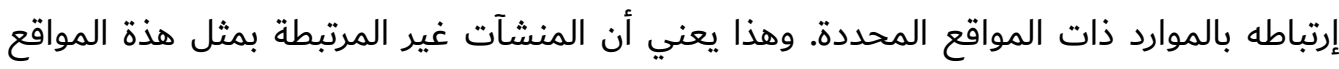

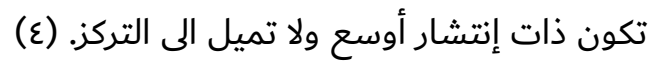

تتركز المنشآت بدرجة أكبر عندما تكون تكاليف النقل أقل وعلى الرغم من ربط Krugman نشأة التجمعات

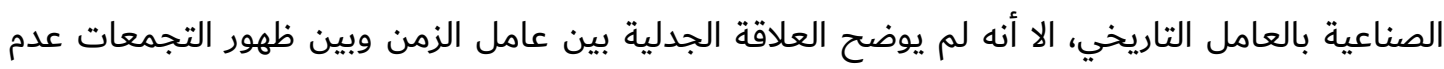
التعرض لتأثير العامل البشري في عملية التركز على اساس ذلك الك التهان : ظهرت

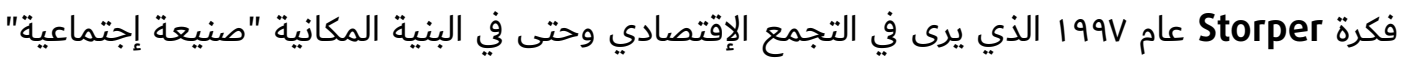

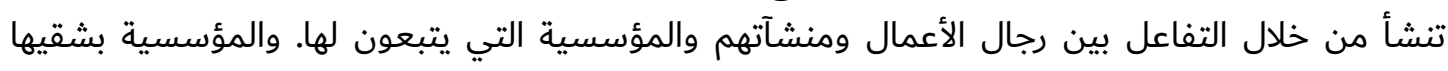

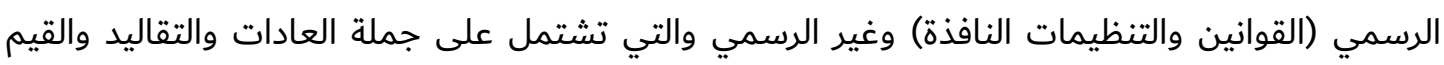
المتعارف عليها (غير المكتوبة) في مجتمع ما هي التي تشكل إطار عملية التفاعل بين رجال النال الأعمال وتصرفاتهم في مجال إختيار الموقع والتعاون والمنافسة.

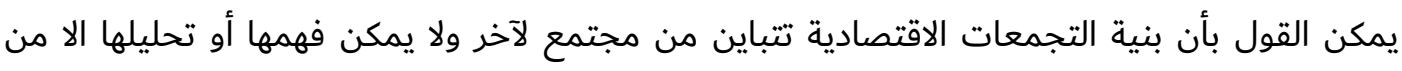

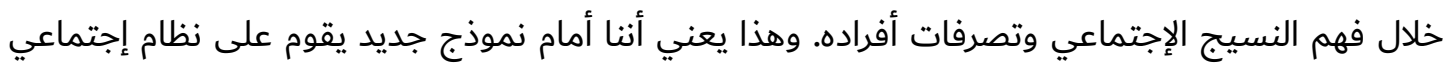
(o) يطلق عليه Model Social-Network 
ومع تراجع - أو بالأحرى فشل نظام إنتاج صناعي قائم على أساس المصنع المنفرد ساد طوال الفترة

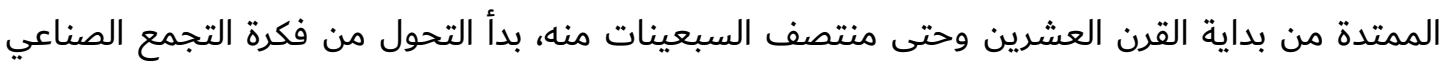

الكلاسيكي الى ما بات يعرف "بالتجمع العنقودي " Cluster (7).

\section{فكرة العناقيد الصناعية}

• عند محاولة تعريف التجمع الصناعي العنقودي فإنه ينبغي بداية العودة الى أفكار ميشائيل بورتر (Michael Porter, 1990) (7)

• والذي يعتبر بحق الأب الروحي لفكرة العنقود الصناعي، سواء من حيث البنية أو من حيث الدور الذي

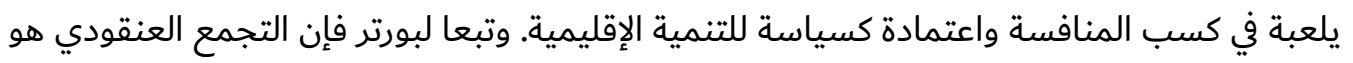
(تركز منشآت إقتصادية متماثلة الإنتاج ومرتبطة بسلسلة قيمة مضافة محددة في موقع ما وتتفاعل

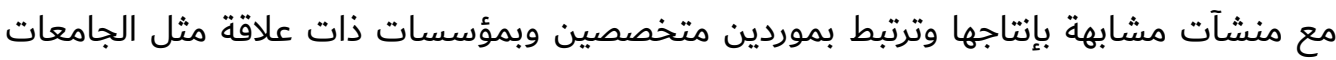

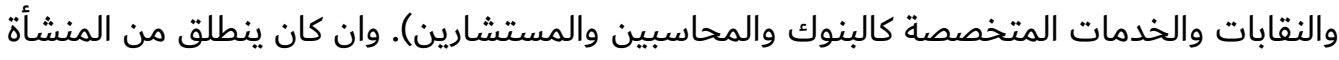

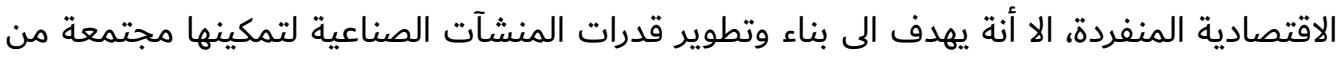

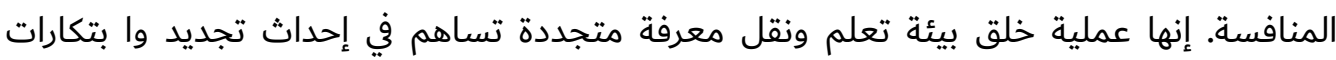

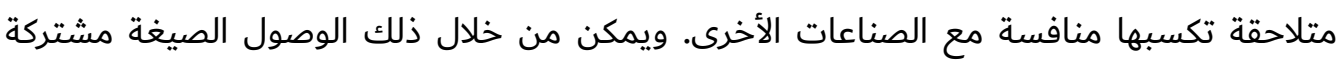

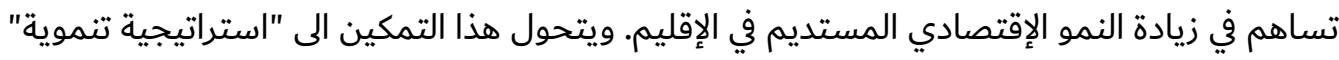
تحفز إنشاء المزيد من الأعمال وتطويرها بنفس الأسلوب السابق.(^).

وظيفة العنقود الصناعي

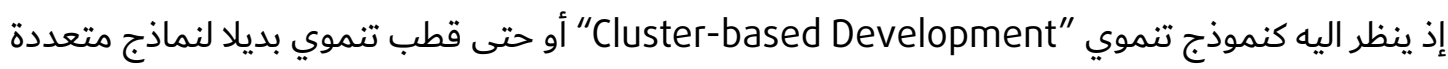

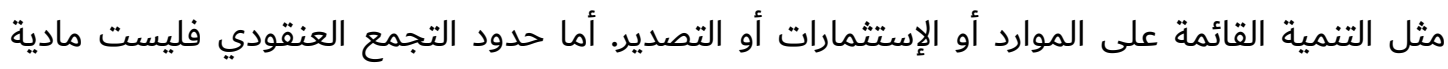

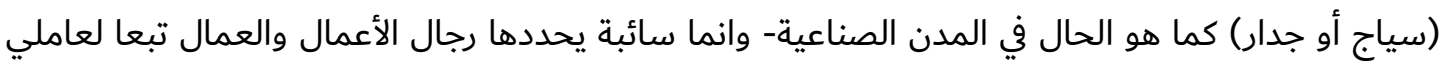

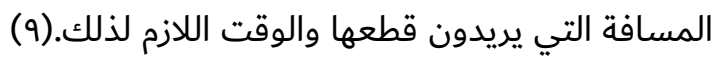

وبهذا تتضمن العناقيد الصناعية عدة عناصر

$$
\text { • وجود منشآت متشابهة في الإنتاج. }
$$

• الإرتباط بمؤسسات علميه واقتصاديه ولوجستيه أخرى

• التخصص إشتراك المنشآت الصناعية بنفس سلسلة القيمة المضافة. ويعني هذا تكامل في الإنتاج يعطي لكل منشأة إمكانية تحقيق قيمة مضافة أعلى. • التقارب الجغرافي ويقصد به تقارب مواقع المنشآت جغرافيا 
إن عملية نمو وتطور العناقيد الصناعية عملية مستمرة وطويلة الأمد قد تدوم لعدة عقود، واغلب العناقيد الحالية نشأت بصورة طبيعية ولم يكن هناك سياسات محددة لصنعها، و يمر العنقود بمراحل متعددة تشات تشكل دورة حياته وتؤار إمكانات العنقود على طول كل مرحلة من هذة المراحل كما تلعب العوامل الخارجية دورا

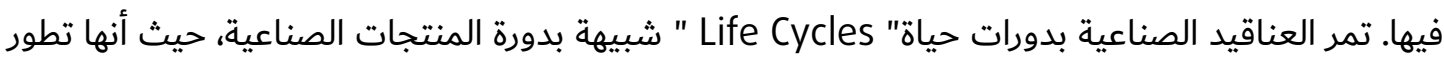

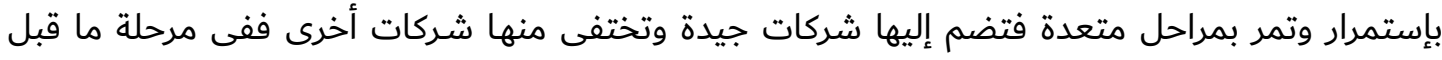

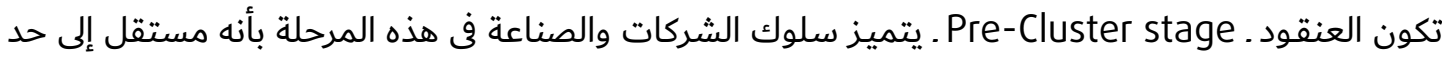
كبير وقليل التفاعل مع المجتمع المحلى. ويولد العنقود من شركة أو شركتين في البداية" الرواد " ويكون الحافز إما توفر مواد خام أو توافر عمالة

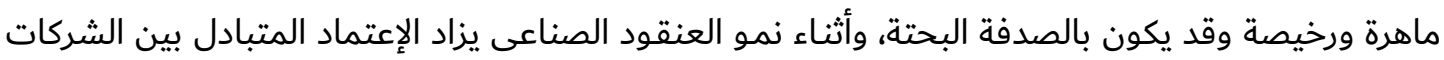

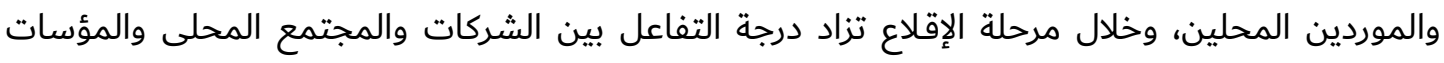

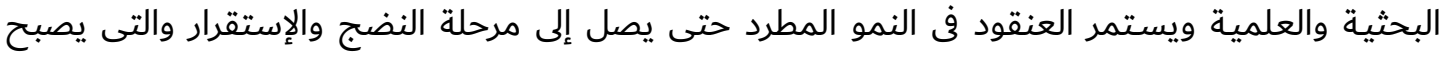

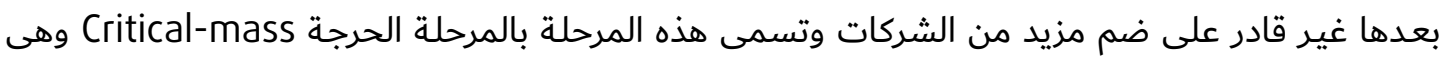

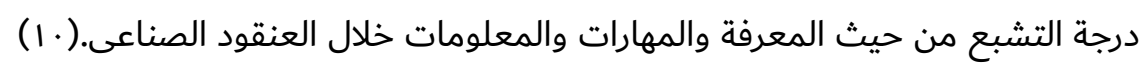

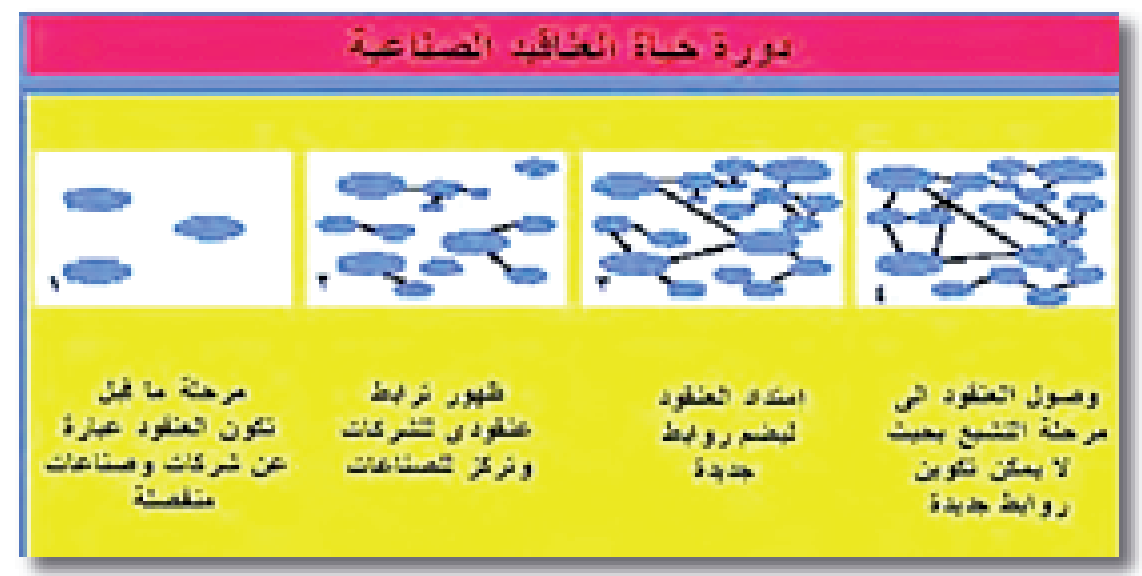

شكل 1: دورة حياة العناقيد الصناعية. المصدر : (·)

ا. مرحلة التحول: وتحدث عندما تتغير التقنيات وعمليات الإنتاج ويتم استبدال منتجات العنقود بمنتجات

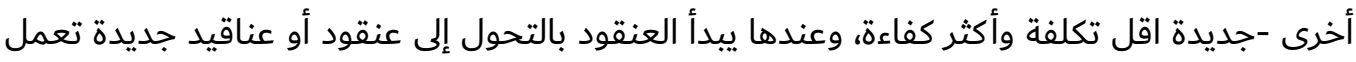

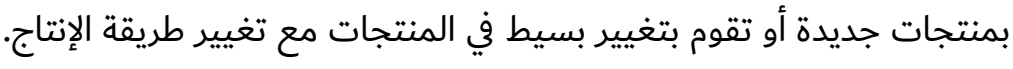

r. مرحلة النضوج : عندها تصبح عملية الإنتاج والترابط بين مؤسسات العنقود عملية روتينية، وتشهد ازدياد عدد المؤسسات الجديدة والمنبثقة، كما تزداد الاستثمارات الأجنبية، وفي هذه المرحلة يتم التركيز

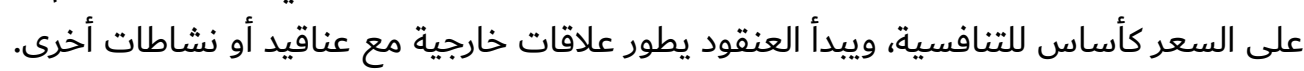
ب. مرحلة النمو : يبدأ عدد المؤسسات بالتزايد ويستقطب المستثمرين المقلدين والمنافسين و يظهر

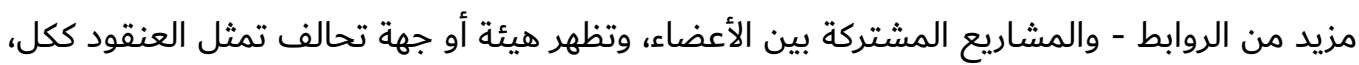

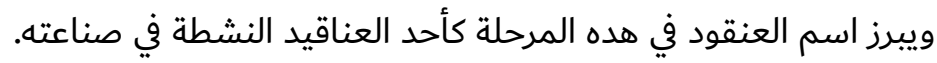




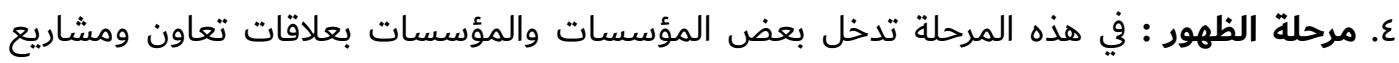

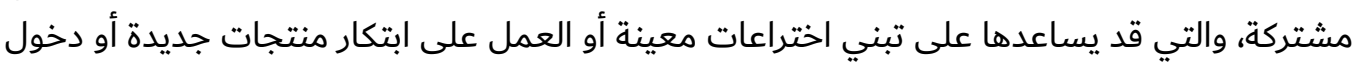
استثمارات جديدة خصوصا الأجنبية منها.

0. مرحلة التجمع : وهي المرحلة التي تبدأ بتجميع عدد قليل من المؤسسات التي تعمل في صناعة معينة في موقع جغرافي محدد، ومن حولها عدد قليل من المؤسسات المساعدة. (111)

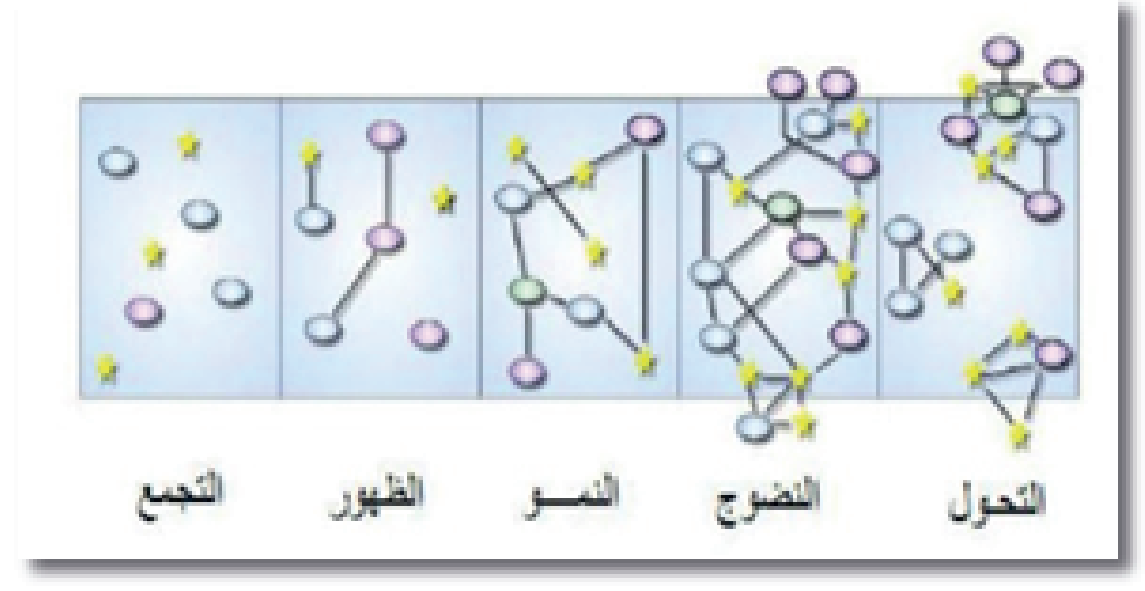

شكل r: مراحل نمو العناقيد الصناعية, المصدر (111)

الابعاد المكونه للعناقيد الصناعية أنواع العناقيد الصناعية

• العناقيد الصناعية حسب النشاة: يكون التجمع بشكل طبيعي تلقائي لتوفر الموارد الطبيعية والمواد الخام أو لوجود المهارات اللازمة لدى السكاع النان.

• العناقيد الصناعية حسب المنتج: عنقود صناعة السيارات في ديترويت وجنوب ألمانيا, خدمات سياحية أو اعلامية هوليود، أو عنقود صناعة الاتصالات) ستوكهولم في فلندا. • العناقيد الصناعية حسب درجة التخصص: وكمثال على ذلك صناعة الأحذية في شمال إيطاليا حيث يوجد عنقود متخصص في صناعة الأحذية يركز على التصاميم والأسماء التجارية ويتمتع بمستوى

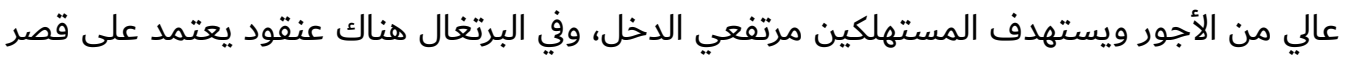
دورة الإنتهاج ومواكبة الموضة ويستهدف متوسطي الدخول في أوربا.

• العناقيد الصناعية حسب نوعية الترابط: راسي وفيه يتكون العنقود من مؤسسة أو بضع مؤسسات

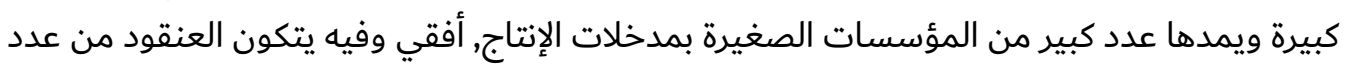

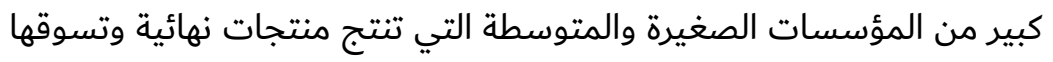




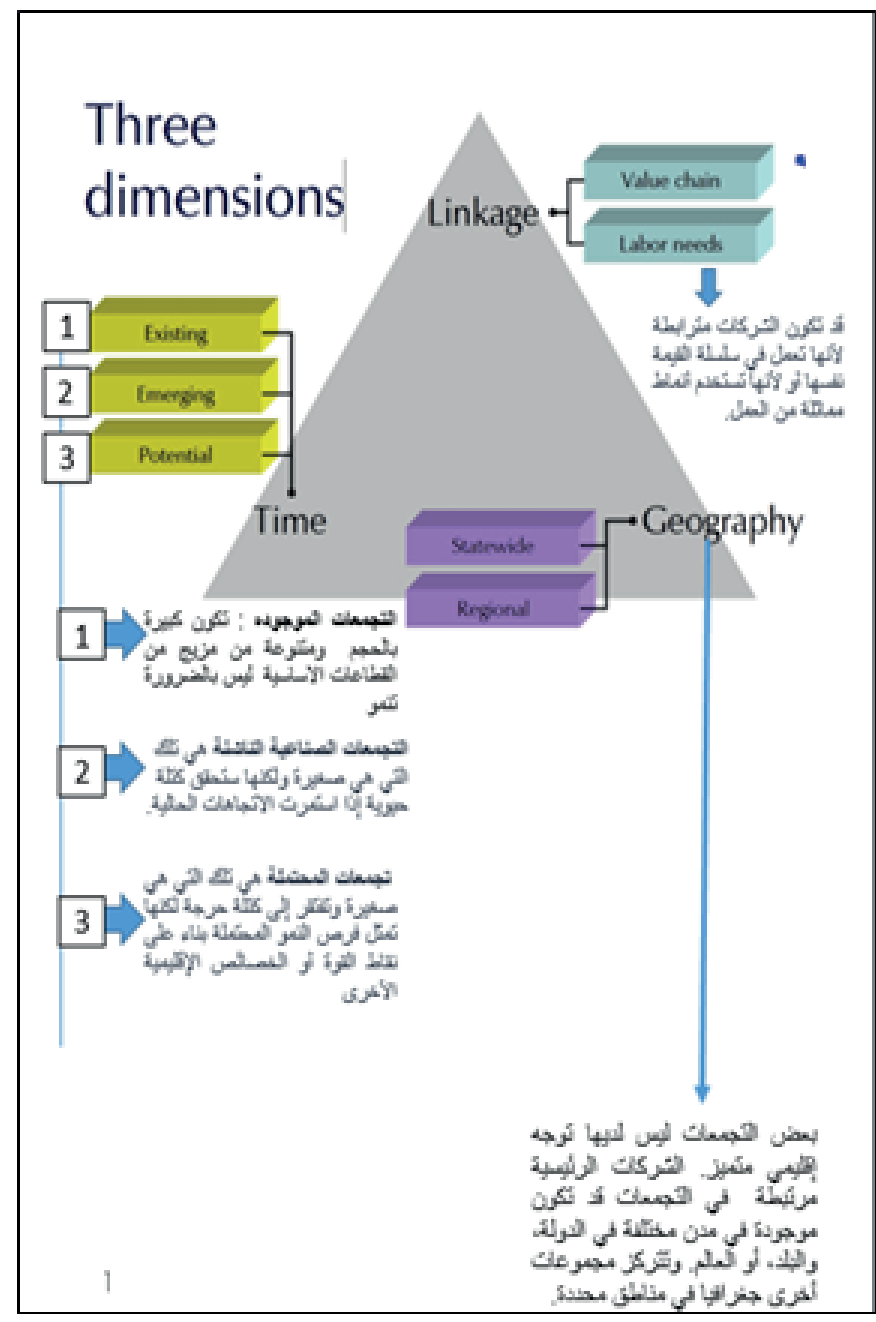

شكل س: الابعاد الثلاثية للعناقيد الصناعية, المصدر الباحثة بالاعتماد على مصدر r|

\section{آليات عمل العناقيد الصناعية}

تقوم آلية عمل العنقود الصناعي على أربعة مبادئ أساسية هي

• التركز الجغرافي: هو أول مبدأ تقوم عليه آلية عمل العناقيد الصناعية تجتمع المؤسسات في مكان نتيجة لوجود ميزات واقعية ملموسة كالموارد الطبيعية أو البينية التحتية.(ب ا ( )

• التخصص: العنقود الفعال يحتاج إلى مؤسسات ذات قوة في تخصصها تتكامل مع بعضها في إنتاج

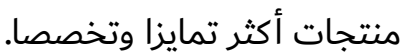

• الابتكارات : وهي المقياس الحقيقي لحيوية وتنافسية العنقود، فعندما تبتكر مؤسسة منتج ما يسارع المنافسون للبحث عن إنتاج منتج منافس.

• المنافسة: إن المنافسة بين المؤسسات من أهم المبادئ من حيث المحافظة على زحم النشاط فالتنافس بين المؤسسات هو الحافز الذي يدفعها نحو الدراسة عن المزيد من الابتكارات وتطوير

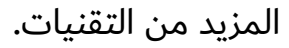


• التعاون: وهو مبدأ لا يتناقض مع المبدأ السابق نمو مؤسسة ناجحة وتنافسية يحفز الطلب من قبل هذه المؤسسة على منتجات المؤسسات الموردة لها.

\section{تجارب العناقيد الصناعية تجربة وادي السيلكيون}

بداية وادي السليكون كانت في خمسينات القرن الماضي والسبب في ذلك جامعة ستانفورد التي تأسست

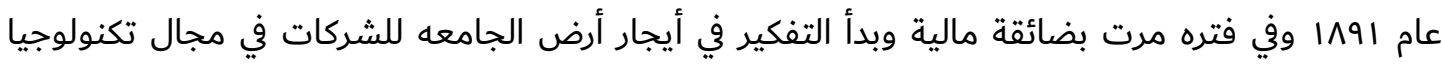

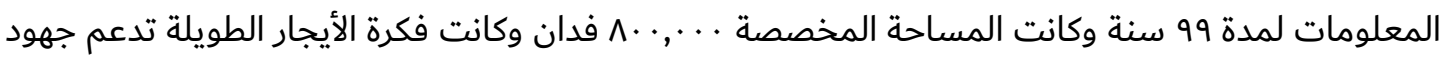

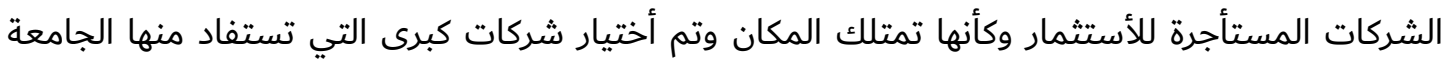

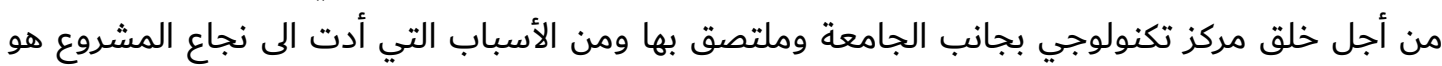

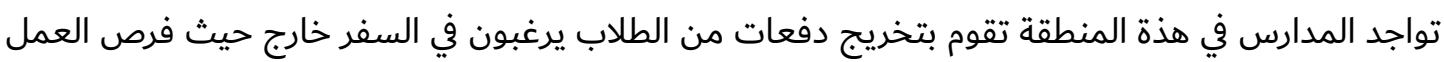

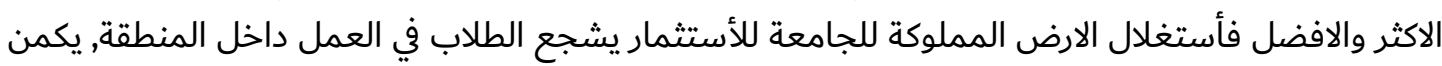

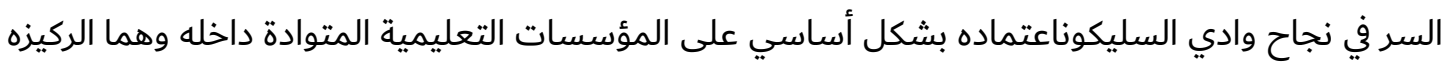

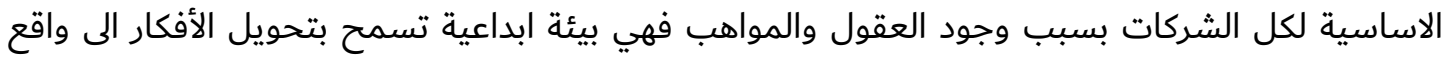

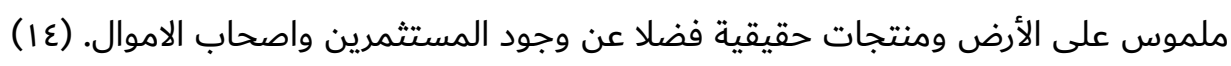

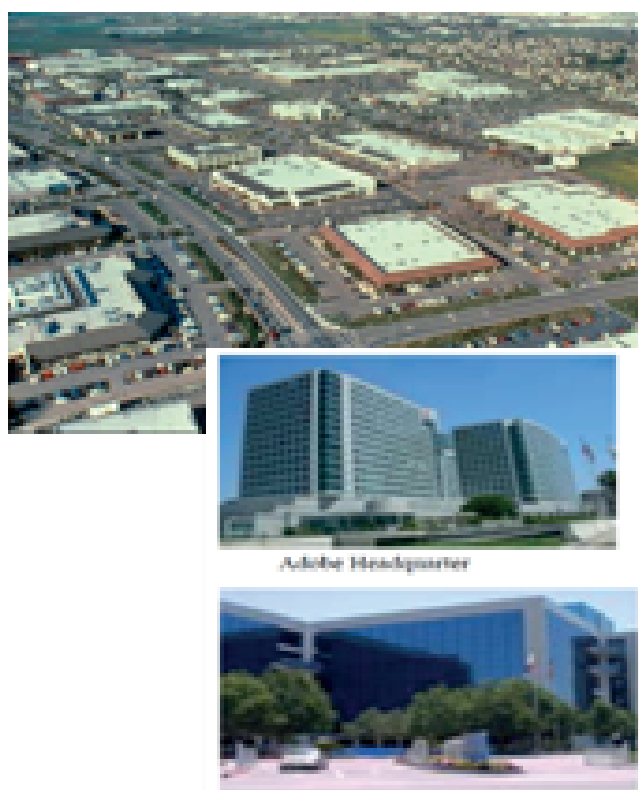

Bated Benelyouster
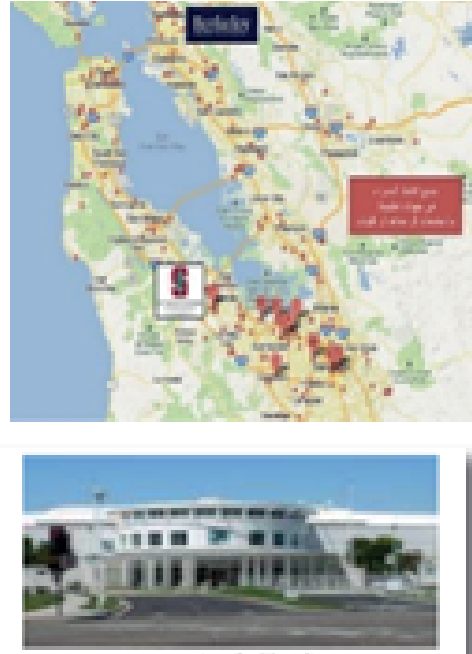

Avele Heobinarier

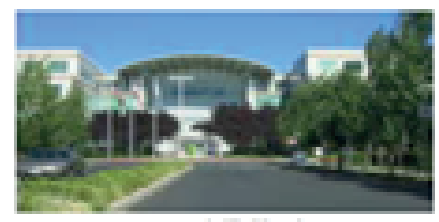

AMD Blentranter

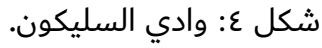


التنمية الاقليمية : تلك التغيرات ـ والتغير من أهم اهتملمات علم الجغرافيا التى تطرأ على حالة اقليم ما

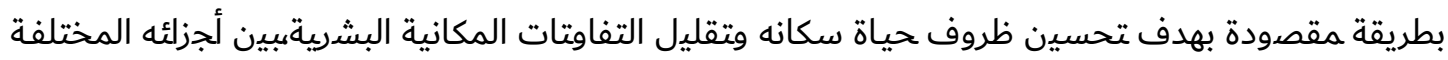
وذلك عن طريق الاستخدام الأمثل لموارده، وتحسين كفاءة إمكاناته البشرية بكافة. تفصيلاتها " يمكن

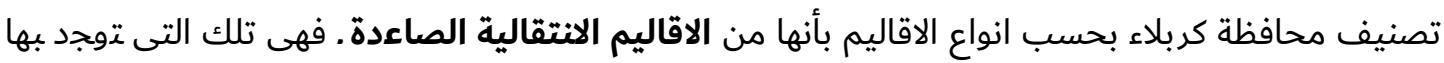

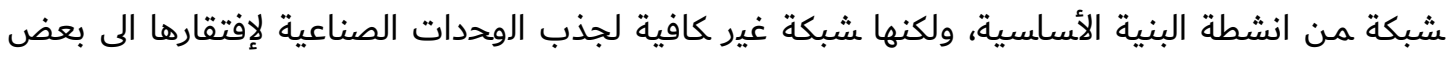

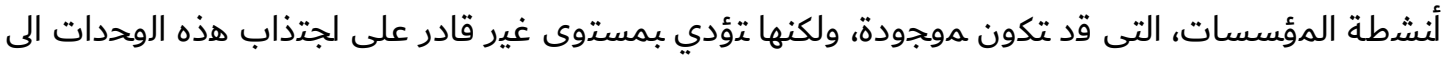

تلك الاقاليم.(10) (10) نظرة عامة على القطاع في محافظة كربلاء من المفترض ان يحتل القطاع الصناعي مكانة ستراتيجية في عملية التطوير الاقتصادي للمحافظة. حيث، ان

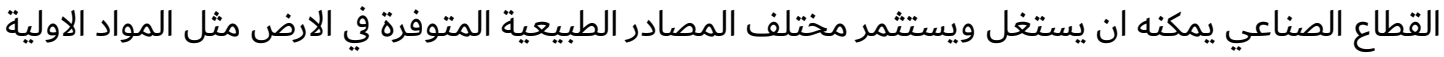

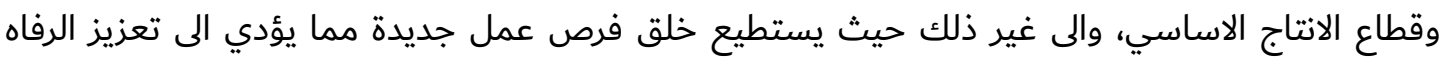

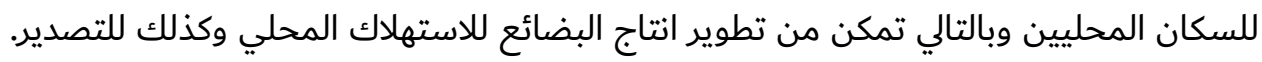

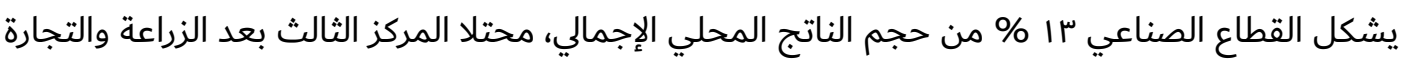

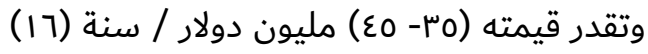

قيمة المنتجات الصناعية بالنسبة للقيمة الكلية للأنتاج في المحافظة باستثناء النفط

\begin{tabular}{|c|c|c|}
\hline مرز باتمبة تمرائ & $\%=$ & أمصان \\
\hline \multirow[t]{2}{*}{0} & 10,3 & أنمر \\
\hline & • & با \\
\hline \multirow[t]{2}{*}{4,10 . } & 6,2 & th \\
\hline & $*$ & أע- \\
\hline 2. & 8,3 & $2 x+5$ \\
\hline 3,1. & 7,2 & تليفت \\
\hline 5,3 & 5,0 & itsis \\
\hline 7,3 & 3,1 & gإl \\
\hline
\end{tabular}

المنشات الصناعية الكبيرة في محافظة كربلاء و العراق

\begin{tabular}{|c|c|c|c|c|c|}
\hline لهان & 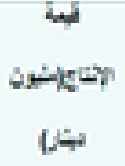 & بئرة) & عد نيتعي & هش نسيتك & \\
\hline 1559745 & 3716181 & 1771566 & 193851 & 495 & IN \\
\hline 324 & 535 & 8699 & 1834 & 25 & $\Delta x_{4} \beta$ \\
\hline 0.0002 & 0.0001 & 0.005 & 0.009 & 0.05 & 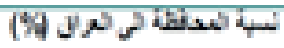 \\
\hline
\end{tabular}




\section{حالة التركز الصناعي في المحافظة}

ان محافظة كربلاء المقدسة تعاني من انخفاض التركز الصناعي عموما لكن هناك توجها نحو نمو الصناعات

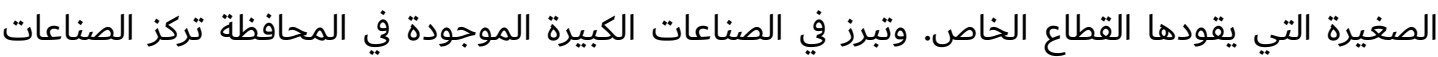
الانشائية

وتهدف خطة التنمية الوطنية الى زيادة الامكانيات الصناعية والتركز السكاني في المحافظات ذات المستوى المنخفض للتنمية تحديدا، وينبغي ان يكون الهدف الرئيسي لاستراتيجية التنمية الصناعية في كربلاء المقدسة

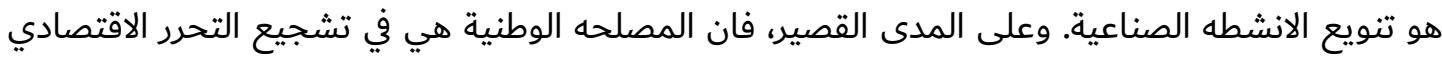

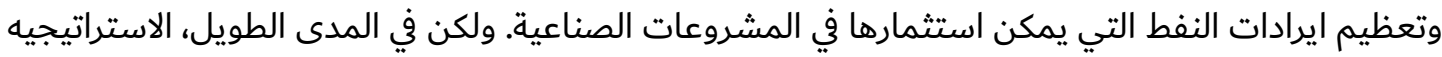
الوطنية تدعو لاعادة هيكلة جذرية للاقتصاد. إن الاستراتيجية تهدف الى زيادة القيمه المضافه للانشطه

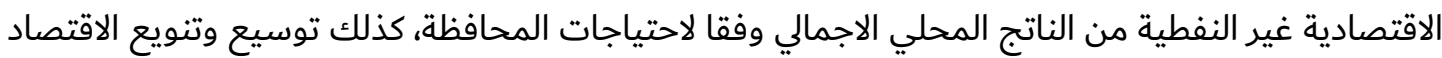

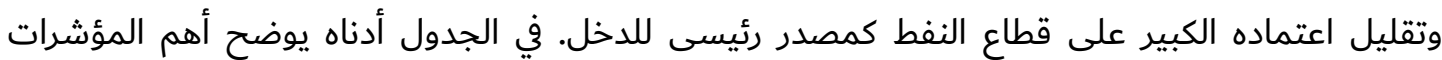
المتعلقة بالقطاع الصناعي في محافظة كربلاء المقدسة,عدد الصناعات، عدد العمال، تكلفة الإنتاج، الأجور والقيمة المضافة.

هذا الشكل يوضح تطبيق مفهوم العناقيد في محافظة كربلاء يتضمن علاقات بين المصانع والشركات

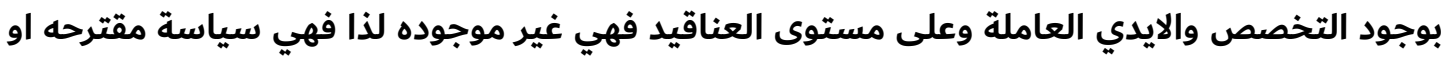

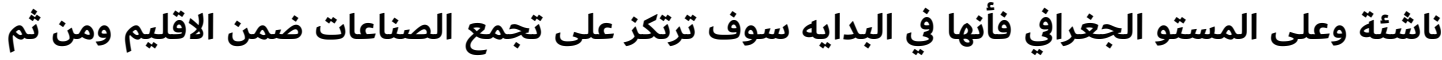
اي بعد نجاح الفكرة ممن الممكن ان ترتبط الصناعات على المستوى العالمي.

\section{آليات عمل العناقيد الصناعية في كربلاء}

ان اليات عمل الغناقيد في محافظة كربلاء تتمحور اولا في وجود الحيز الجغرافي المتمثل بالمحافظة مع الماء وجود التخصص في الصناعات حيث توجد صناعة الانشاءات ومواد البناء ممكن ان تشكل تجمع عنقودي او الصناعة الغذائية وبعد تكوين التجمع سوف تبدأ مرحله الابتكار والمنافسة والتعاون التي تضمن التمن نجاء ماء

\section{مؤشرات التنمية الاقتصادية}

• تعد التنمية الاقليمية احد الابعاد للتنمية القومية، فأن العمل بالبعد التنموي الاقليمي يؤدي الى زيادة

$$
\text { معدلات النمو للمجتمع. }
$$

• الحد من الفروقات بين الاقاليم وبين الاجزاء من خلال تنمية اقليمية متوازنة في الابعاد المختلفة الاقتصادية والعمرانية والاجتماعية.

• تقليل الفروقات بين الاقاليم بالتاثير على الطلب وتخفيض معدلات البطالة في المناطق ودعم مستلزمات الحياة الاجتماعية والثقافية لسكان الاقاليم بضمنها الحفاظ والاستعمال الامثل للموارد الطبيعية والثقافية والمرافق العامة. 


\begin{tabular}{|c|c|c|c|c|c|c|}
\hline 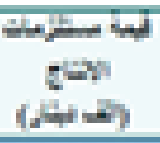 & $\begin{array}{l}4-N+4 \\
4+4+1\end{array}$ & $\begin{array}{c}\text { dith } \\
4+4+7\end{array}$ & 4 & Ar & 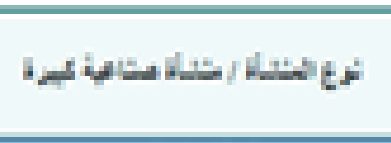 & $=$ \\
\hline Wh1110 & 714440 & 24165 & 55 & $4 y$ & Jak julde & \pm \\
\hline IRM.SH & 1HAT) & LOSW & 4 & 40 & 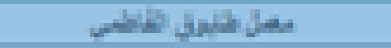 & 2 \\
\hline A44 & คD1.14 & 17wa & $\mathbf{H}$ & ind & 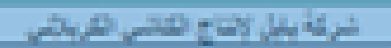 & J \\
\hline dublrt & trosa & 21700 & 4 & $-14 \mathrm{bi}$ & 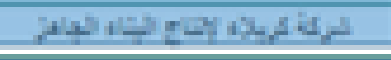 & 4 \\
\hline Tollso & $2004 \mathrm{~kg}$ & Ixwots & 44 & sibju & t. & 9 \\
\hline 404112 & 124: & 111,in & 147 & $A \Delta+j$ & $5 i+4-7+44 j$ & 6 \\
\hline Whin & 214ni & 4204 & 14 & ondu & 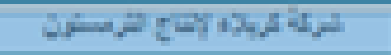 & 7 \\
\hline 918Вน & HES & HA1S & 194 & +2 & $+2=3+k+p^{2}+5$ & 8 \\
\hline 11841,115 & MSIS & Whe & 24 & $x=$ & 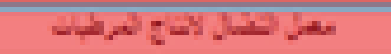 & 9 \\
\hline \multirow[t]{6}{*}{ PHL.7L0 } & 14a & 104140 & 4 & sthe & $2+5+4+4=$ & 10 \\
\hline & 45,414 & 12,600 & 9 & 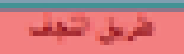 & 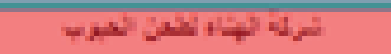 & 11 \\
\hline & FH.X4 & 157\% & 2 & 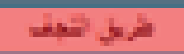 & 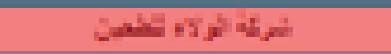 & 12 \\
\hline & 204319 & H410 & 14 & $4 \rightarrow$ & 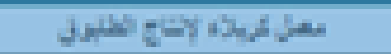 & 13 \\
\hline & & & & 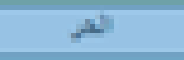 & Af Jimlo ja & 14 \\
\hline & Mas & 21440 & 41 & 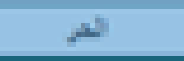 & Juth gur stap & 15 \\
\hline MHLG7 & hill & 1030 & 4 & 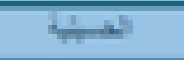 & 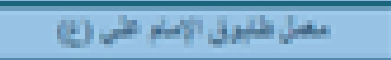 & 16 \\
\hline Din & 214hI4 & 17540 & 44 & +1 & 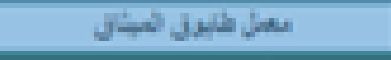 & 17 \\
\hline \multirow[t]{4}{*}{ Inots } & 52.147 & 6148 & I7 & 4 & $4+2-7+4 y$ & 18 \\
\hline & 194,Bม & 12744 & 8 & $\because 2$ & 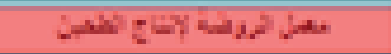 & 19 \\
\hline & 74,441 & 190149 & W & +4 & 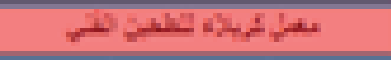 & 24 \\
\hline & 47.724 & IAPISA & 11 & 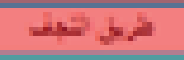 & 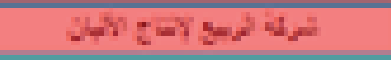 & 21 \\
\hline \multirow[t]{2}{*}{ 1184h } & \%5нm: & 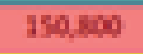 & 21 & $-4+2$ & ith jonthes & 22 \\
\hline & & & $=$ & +4 & 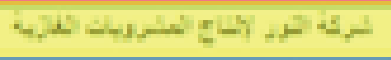 & 23 \\
\hline 11,\$4 & HLIS & 14he & $\overline{8}$ & + & 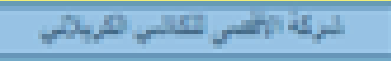 & 24 \\
\hline 5asp114 & 200461 & 1045sa & 185 & $-\mu$ & +hy & 25 \\
\hline
\end{tabular}

شكل 0: المنشات الصناعية الكبيرة في محافظة كربلاء المقدسة عام r| ·.

• تنشيط الفعالية الاقتصادية وزيادة الدخل والانتاج في المناطق الفقيرة اقتصادياً عن طريق توجيه

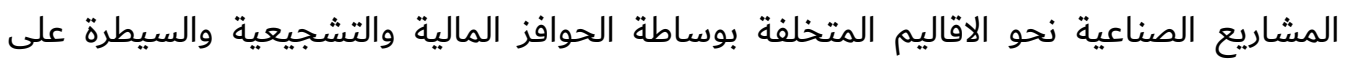

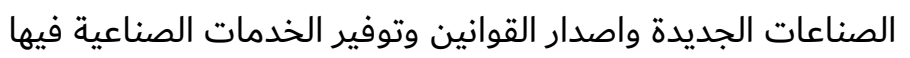

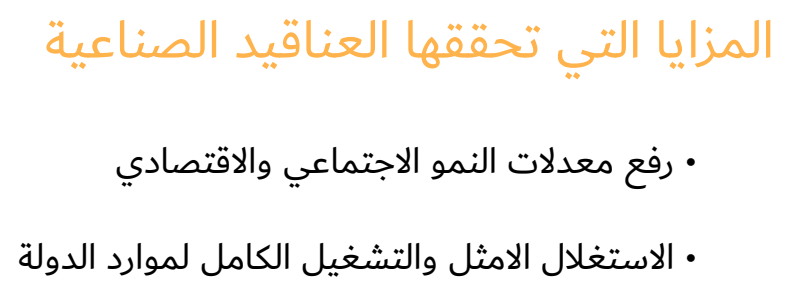




\section{Three dimensions}
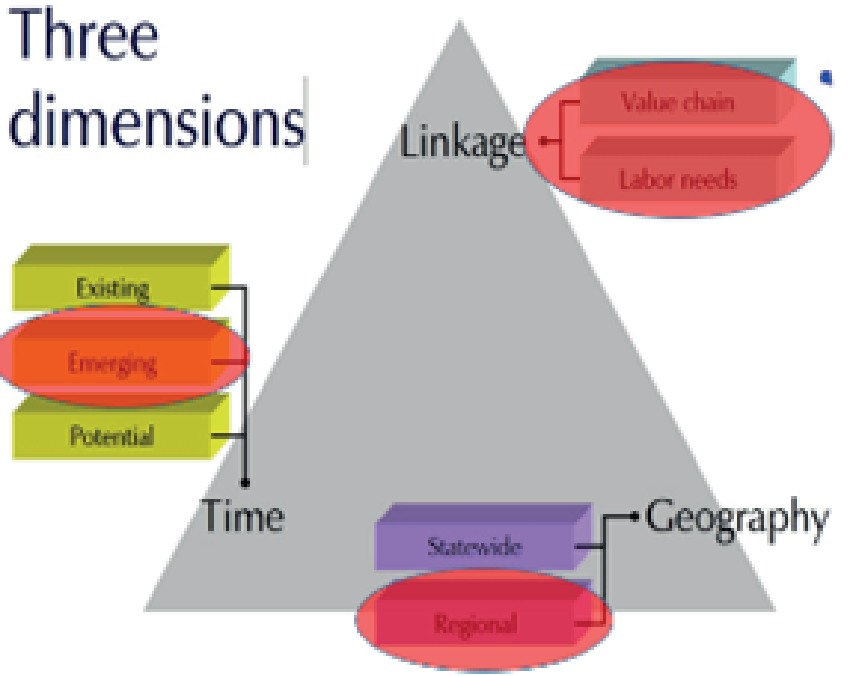

شكل 7: يوضح الابعاد للعناقيد الصناعية بتطبيقها على محافظة كربلاء. الباحث بالاعتماد على مصدر Ir

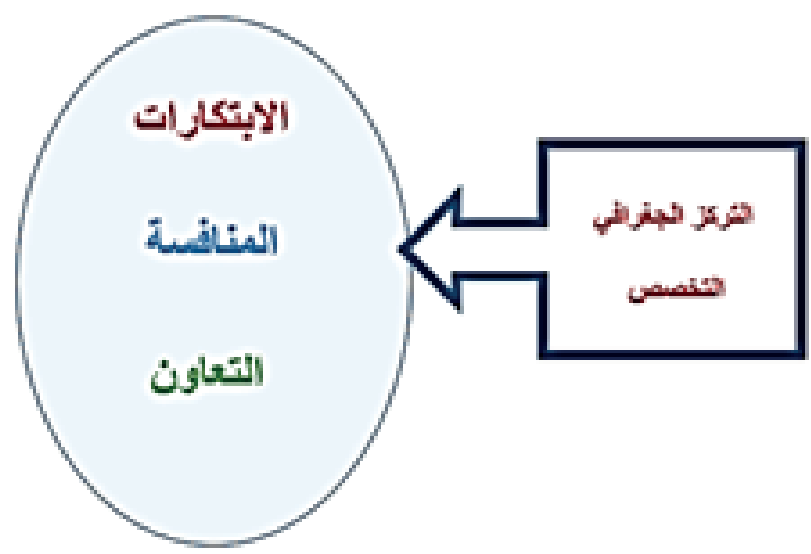

شكل V: يوضح اليات نجاع العناقيد الصناعية. المصدر الباحث
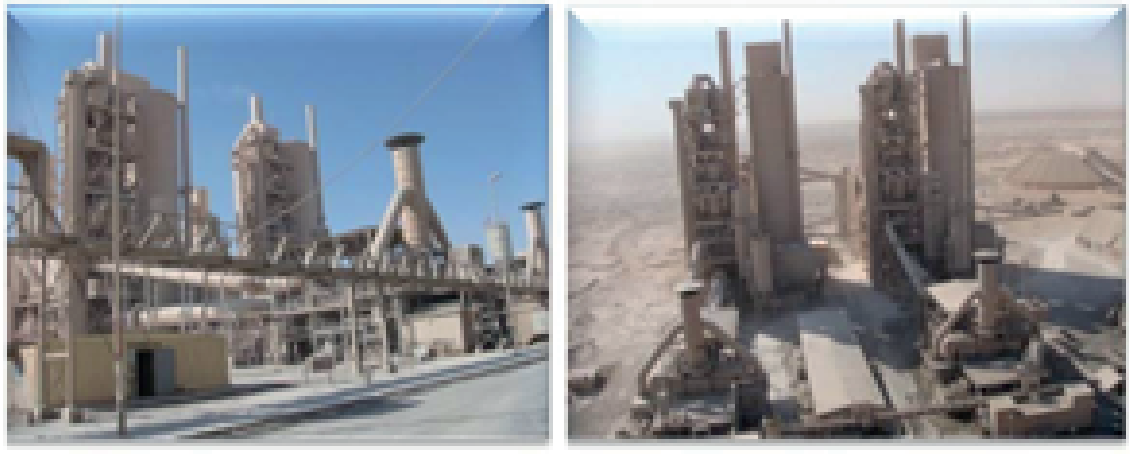

شكل ^: معمل اسمنت كربلاء.

• تحتقيق التنمية الصناعية

• جذب الاستثمارات المحلية والاجنبية

• تنمية المنشات الصغيرة والمتوسطة 

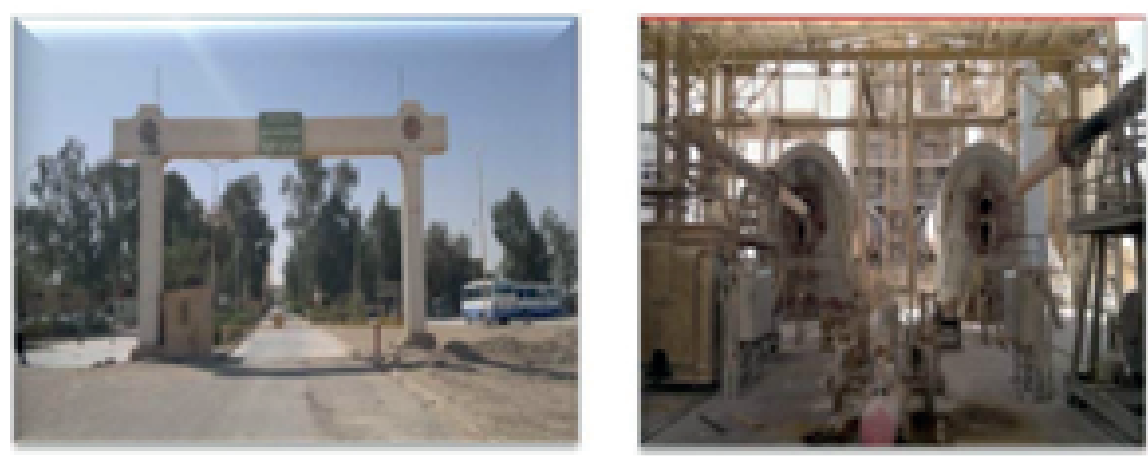

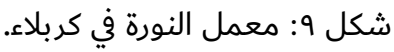

$$
\text { • خفض معدلات الفقر معدلات البطالة }
$$

• تشجيع الابتكار والتطوير من خلال المنافسة

بعد بيان مؤشرات التنمية الاقليمية وبيان الاهداف والمزايا التي تحققها العناقيد الصناعية نستنتج

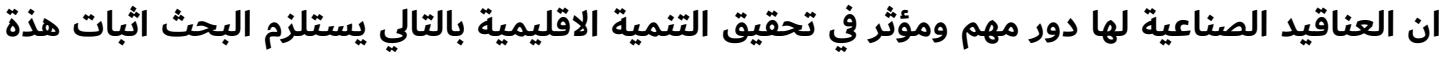
العلاقة رياضيا من خلال تحليل الانحدار حيث تم تحديد المتغير المعتمد وهو الناتج المحلي الاجمالي

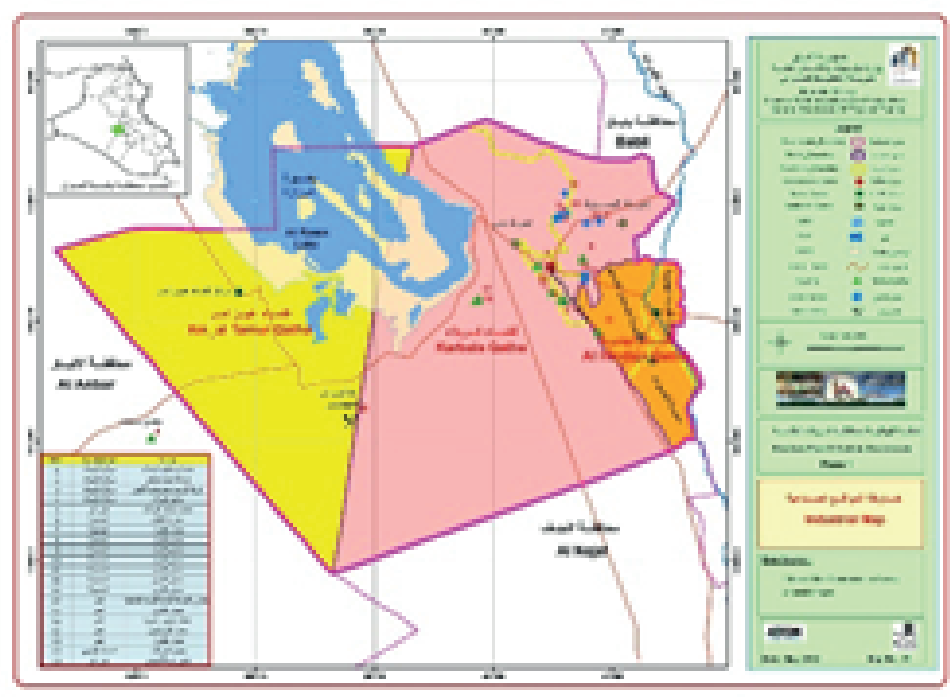

والمتغيرات المستقلة والتي تتمثل 1. اعداد المنشات r. اعداد العاملين في المنشات

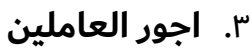


ع. قيمة الانتاج

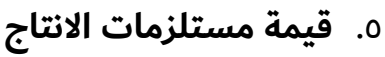

الخارطة توضع توزيع المناطق الصناعية في محافظة كربلاء

\begin{tabular}{|c|c|c|c|c|c|c|}
\hline قالاتثلزمات & قيمة الانتاج & اجور العاملين & عداملين & علدأت & المحلي & \\
\hline $\begin{array}{r}1.400 .0 \\
00\end{array}$ & 19.707 .000 & 8.107 .000 & 1928 & 729 & ترليون 6.4 & كربلاء \\
\hline 410.000 & 5.776 .000 & 2.367 .000 & 565 & 213 & نرليون 2.4 & الهندية \\
\hline 603.400 & 8.494 .000 & 3.494 .000 & 831 & 314 & نرليون 1.2 & تمرن \\
\hline
\end{tabular}

من خلال جمع المعلومات تبين ان تركز النشاط الصناعي بوجود المنشات الصناعية يكون قي قضاء

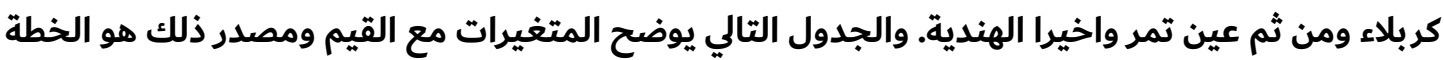

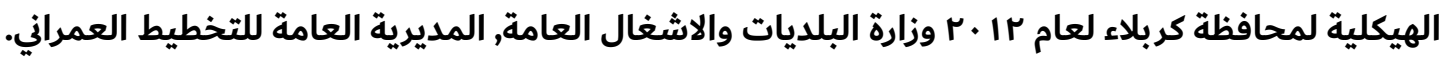

ANOVAB

\begin{tabular}{|ll|r|r|r|r|r|}
\hline Model & & \multicolumn{1}{|c|}{$\begin{array}{c}\text { Sum of } \\
\text { Squares }\end{array}$} & df & Mean Square & F & Sig. \\
\hline 1 & Regression & 12502 & 1 & 12.502 & 5.378 & $259^{3}$ \\
& Residual & 2325 & 1 & 2.325 & & \\
& Total & 14.827 & 2 & & & \\
\hline
\end{tabular}

a. Predictors: (Constant), $x 5$

b. Dependent Variable: y

فن خلال ماتم ذكره من محددات وعوامل يمكن القول ان البيئة الصناعية في محافظة كربلاء لا تتفق

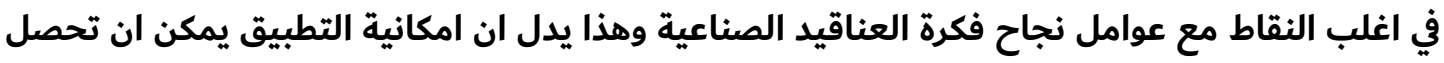

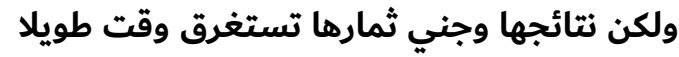
نتائج الاختبار ان هدف التحليل هو بيان وجود العلاقة بين مؤشر التنمية وهو المتغير المعتمد والمتمثل بالناتج

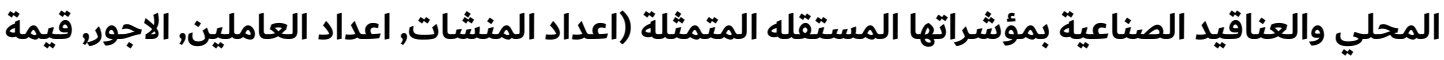

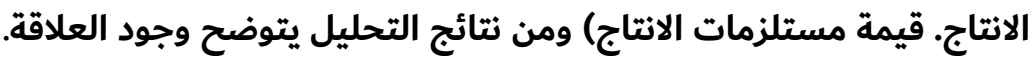

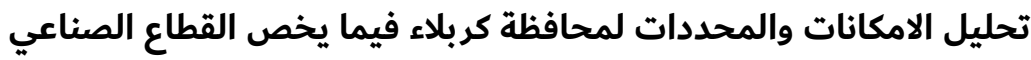

نقاط القوة: 


\section{Coetficientsis}

\begin{tabular}{|c|c|c|c|c|c|c|c|c|}
\hline \multirow{2}{*}{\multicolumn{2}{|c|}{ Hodeal }} & \multicolumn{2}{|c|}{$\begin{array}{c}\text { Unsiandorobed } \\
\text { Coefficents }\end{array}$} & \multirow{2}{*}{$\begin{array}{l}\text { Slanderosed } \\
\text { Coefficients } \\
\text { Beita }\end{array}$} & \multirow[b]{2}{*}{1} & \multirow[b]{2}{*}{$\mathrm{Sig}$} & \multicolumn{2}{|c|}{ 958 Cortidence hitenal iov 8} \\
\hline & & $B$ & Std Eror & & & & Lower Bound & Usper Bound \\
\hline & (Constant) & .990 & 1.872 & & .268 & .834 & 24287 & 23.290 \\
\hline & 15 & 4.784 & 2064 & 918 & 2319 & 269 & 21338 & 30.800 \\
\hline
\end{tabular}

a Dependeantl|vaidaley

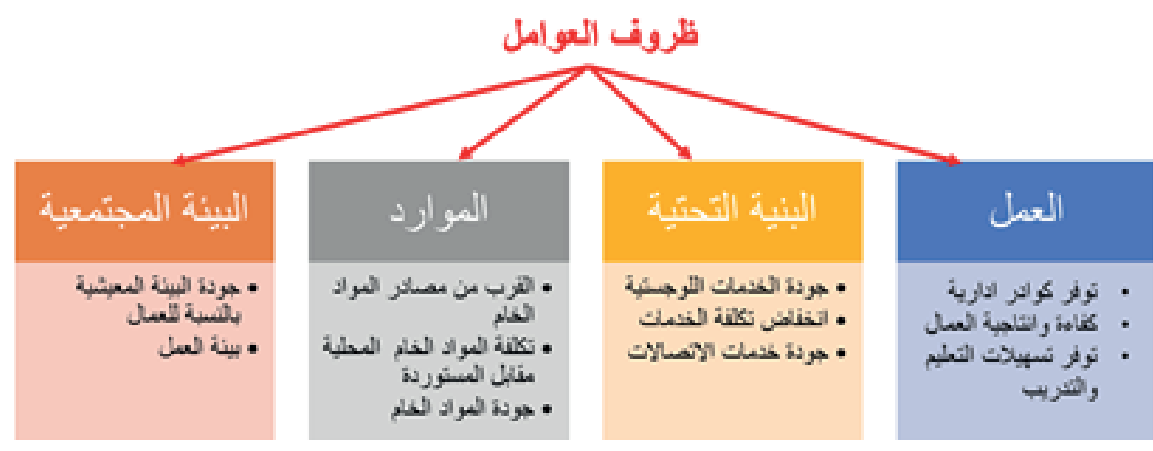

ا. التنوع والتخصص في الصناعات.

r. وجود القاعده الاساسية للصناعه بوجود مصانع متكاملة. س.. المواد الاوليه الخام للصناعات والتي تعتبر من المدخلات التي تقلل من كلف الانتاج. ع. وجود الايدي العاملة المحلية. 0. وجود الاسواق الكبيرة باعتبارها مدينه جاذبة للسياح (السياحة الدينية)

نقاط الضعف:

ا. مشكلة التكنولوجيا:عدم وجود المعارض المتخصصة ادى الى صعوبة الحصول على التكنولوجيا الحديثة والمتطورة من المناشئ العالمية فضلا عن ارتفاع التكاليف وعدم قدرة المشاريع القائمة على الى التيكائ

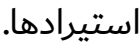
r. تراجع اقتصاديات الإنتاج: صغر حجم المعامل وانخفاض طاقتها الإنتاجية وارتفاع متوسط كلف الإنتاج. استخدام المعامل لأساليب إنتاج قديمة وغير كفوءة.

القرب من العاصمة وخطوط النقل, وجود المصانع وتنوعها وارتباطتها يؤدي الى امكانية تحقيق مفهوم العناقيد بالتالي يؤدي الى تنمية اقتصادية للاقليم وبالتالي اقليمية والعالعالية ا. القضاء على البطاله من خلال تشغيل الايدي العاملة وبالتالي فرصه التعليم والثقافة للعاملين. 
r. العناقيد تصبح بمثابه اقطاب نمو يشجع على اقامة مستقرات بشرية تخفف عن المدينة الام.

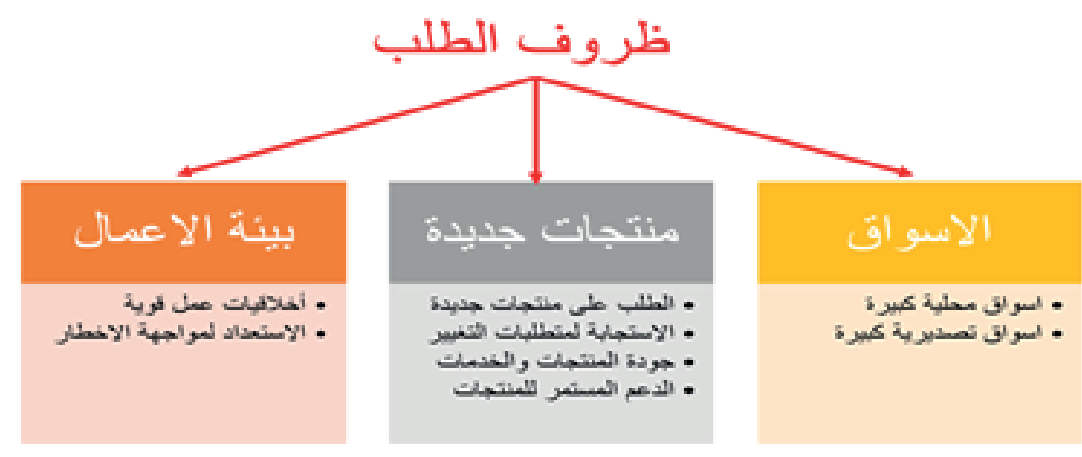

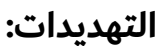

عدم مقدرة الاستثمار الاجنبي ونقل التكنولوجيا بسبب مشاكل الاستقرار الامني,عدم وجود بنية تحتيه اساسية, التنافس والابتكار من المحتمل ان يؤدي الى اغراق السوق بالمنتجات الاجنبية وتوقف المنتجات المحلية.

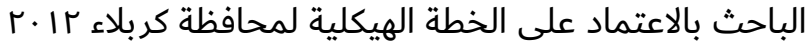
محددات نجاح العناقيد الصناعية ان تطبيق مفهوم العناقيد ينبغي معرفة العوامل والمحددات التي على اساسها يتم نجاح العناقيد

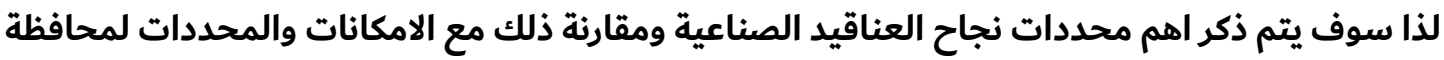
كربلاء والتي تخص الجانب الصناعي.

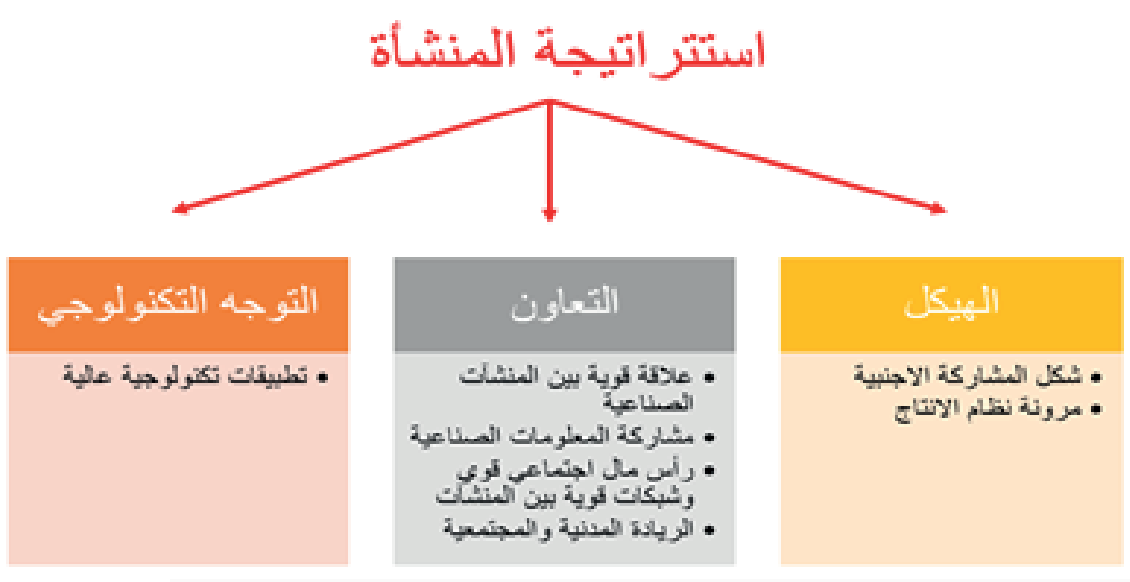

• ان لسياسات الاستقطاب الصناعية امكانات مؤثرة في التنمية الاقتصادية، لكن من المحتمل ان يتحقق

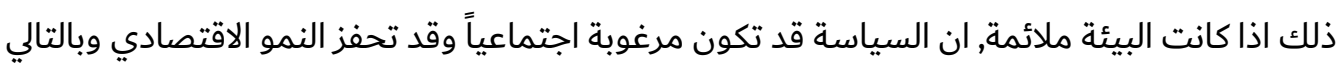
التنمية. 
• أهمية العناقيد الصناعية بالنسبة لاقتصاديات الدول من حيث الاستغلال الأمثل للموارد، و زيادة الصادرات، وتنمية المنشآت الصغيرة والمتوسطة، فضلا عن جذب المزيد من الاستثمارات المحلية والأجنبية، ودورها في التنمية. • من خلال دراسة واقع الحال لمحافظة كربلاء يمكن استتتاج ان القطاع الصناعي يمثل نسبة كبيرة من

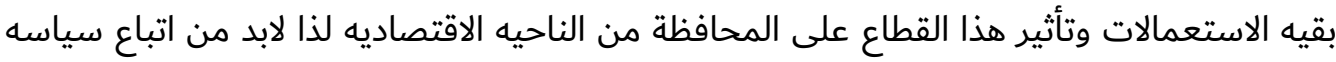
لتطوير هذا القطاع • تحتاج محافظة كربلاء الى بعض الاساليب والسياسات وذلك لتطوير مجال القطاع الصناعي وبالتالي تتلائم مع عوامل نجاح العناقيد الصناعية لامكانية تطبيقها

• هنالك علاقة بين تطبيق سياسة العناقيد الصناعية كسياسه استقطاب حديثه حيث بوجود العناقيد الصناعيه يمكن تحقيق التنمية الاقليميه من خلال تحقيق التنمية الاقتصاديه..... ولكن التساؤل هل هل

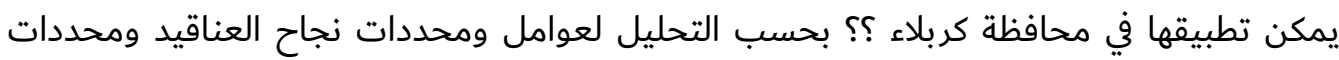

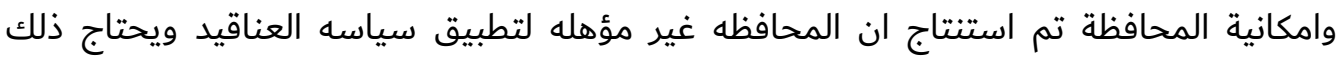
توظيف وعمل للبيئة من اجل نجاح المفهوم.

يوصي البحث بمحاولة الاخذ بنظر الاعتبار مفهوم العناقيد الصناعية كسياسة تهدف الى التنمية المكانية

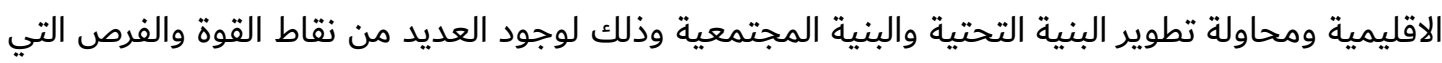

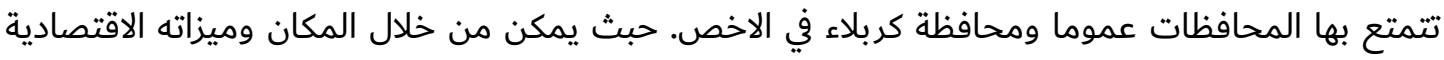
تطوير اقليم بأكمله وبميزات اقتصادية واجتماعية وثقافية وتكنولوجية.

[1] (د. احمد محمد عبد العال , مراكز النمو بين النظرية والتطبيق , المجله الجغرافية العربيه ,الجمعية

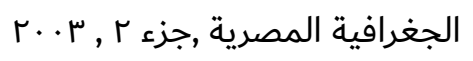

[2] Timothy Frye, The Perils of Polarization: Economic Performance in the Postcommunist World,2002

[3] Krugman, Paul. 1991a. Geography and Trade. Cambridge: MIT Press

[4] Bathelt, H. (2001): The Rise of a New Cultural Products Industry Cluster in Germany: the Case of the Leipzig Media Industry

[5] Karlson ,c Edt.). 2008. Handbook of Research on Cluster Theory. Cheltenham, UK and Northampton, MA, USA.

[6] ketels, C.H.M. 2003. The Development of the Cluster Concept Present Experiences and Further Developments

[7] The Competitive Advantage of Nations, M. E. Porter,1990 
[8] Cluster Theory and Practice: Advantages for the Small Business Locating in a Vibrant Cluster, Adrian T.H. Kuah Huddersfield University Business School Huddersfield UK

[9] Rosenfeld, S.A. 2002. Just Clusters -Economic development strategies that reach more people and places, A Synthesis of Experience, Carrboro (North Carolina [ • [ ممدوح محمد مصطفى, إستراتيجية توطين المشروعات الصناعية فى مصر , دراسة حالة : إقليم جنوب

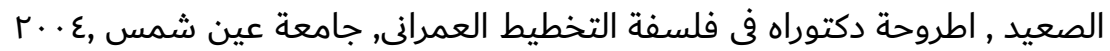

[11] Clunet, 2008. Cluster Policy Guidelines Report. Pro Inno Europe, INNONETS CLUNET

[12] Edward Feser, Industry Clusters and Economic Development: A Learning Resource,2004

[13] Cities and clusters in Europe, How cities are supporting clusters,2008

[14] Rogers, E.M., \& Laresoen, J.K., Silicon Valley Fever, Growth of High Technology Culture, Basic Books, Inc.,Publishers, New York, 1984

$$
\begin{aligned}
& \text { [10] .د. احمد محمد عبد العال , لمدن الجديدة والتنمية الاقليمية فى مصر , }
\end{aligned}
$$

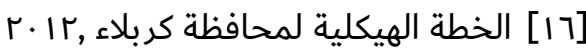

\section{References}

[1] Dr. Ahmed Mohamed Abdel Aal, Growth centers between theory and practice, Arab Geographical Journal, Egyptian Geographical Society, Part 2, 2003.

[2] Timothy Frye, the Perils of Polarization: Economic Performance in the Postcommunist World, 2002.

[3] Krugman, Paul. 1991a. Geography and Trade. Cambridge: MIT Press.

[4] Bathelt, H. (2001): The Rise of a New Cultural Products Industry Cluster in Germany: the Case of the Leipzig Media Industry.

[5] Karlson, c Edt.). 2008. Handbook of Research on Cluster Theory. Cheltenham, UK and Northampton, MA, USA.

[6] ketels, C.H.M. 2003. The Development of the Cluster Concept Present Experiences and Further Developments.

[7] The Competitive Advantage of Nations, M. E. Porter, 1990.

[8] Cluster Theory and Practice: Advantages for the Small Business Locating in a Vibrant Cluster, Adrian T.H. Kuah Huddersfield University Business School Huddersfield UK.

[9] Rosenfeld, S.A. 2002. Just Clusters -Economic development strategies that reach more people and places, A Synthesis of Experience, Carrboro (North Carolina. 
[10] Mamdouh Mohamed Mustafa, Strategy of Localization of Industrial Projects in Egypt, Case Study: Southern Upper Egypt, PhD Thesis in Urban Planning Philosophy, Ain Shams University, 2004.

[11] Clunet, 2008. Cluster Policy Guidelines Report. Pro Inno Europe, INNONETS CLUNET.

[12] Edward Feser, Industry Clusters and Economic Development: A Learning Resource, 2004.

[13] Cities and clusters in Europe, How cities are supporting clusters, 2008.

[14] Rogers, E.M., \& Laresoen, J.K., Silicon Valley Fever, Growth of High Technology Culture, Basic Books,Inc.,Publishers, New York, 1984.

[15] Dr. Ahmed Mohamed Abdel Aal, for the new cities and regional development in Egypt.

[16] The structural plan of Karbala Governorate, 2012. 